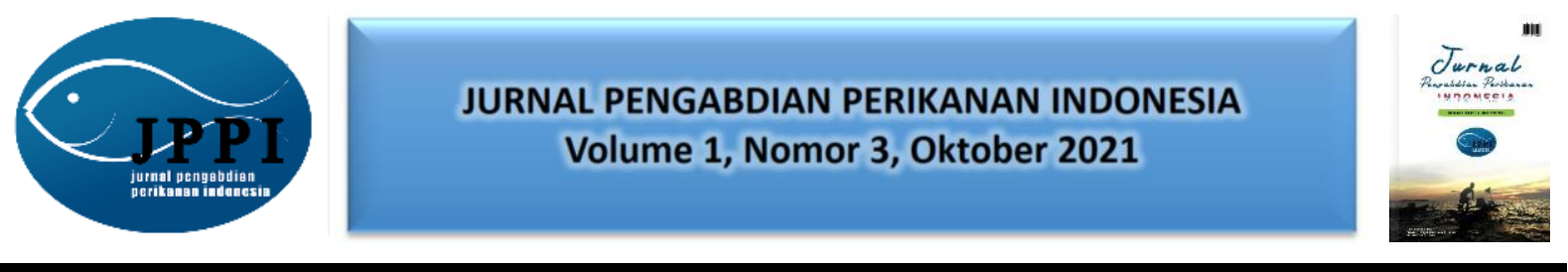

\title{
UPAYA PENURUNAN BAHAN ORGANIK AIR SISA BUDIDAYA UDANG VANAME (Litopenaeus vannamei) DENGAN KONSORSIUM BAKTERI DAN KEPADATAN Chlorella sp. YANG BERBEDA
}

\author{
Rizky Kusma Pratiwi", Diana Arfiati \\ Program Studi Manajemen Sumberdaya Perairan Universitas Brawijaya \\ JI. Veteran, Ketawanggede, Kec. Lowokwaru, Kota Malang, Jawa Timur 65145 \\ *Alamat korespondensi : rkpratiwi@student.ub.ac.id \\ (Tanggal Submission: : 9 September 2021, Tanggal Accepted : 31 Oktober 2021)
}

\begin{abstract}
Keyword: $\quad$ Abstrak:
bahan organik, Pengolahan limbah cair sisa budidaya udang di tambak perlu dilakukan sebelum bakteri, air limbah tersebut masuk ke perairan umum. Dalam proses penurunan bahan karbondioksida, organik selalu diperoleh kadar $\mathrm{CO} 2$ yang tinggi bahkan melebihi ambang batas mikroalga untuk perairan umum. Tujuan dari kegiatan ini yaitu untuk mendapatkan kadar bahan organik terendah dan mengetahui kepadatan terbaik dari mikroalga (Chlorella sp.) yang dapat menurunkan kadar $\mathrm{CO}_{2}$ sampai tingkat terendah dengan waktu tercepat. Metode penelitian adalah RAL dengan 6 perlakuan , 2 kontrol dan 3 ulangan. Masing-masing bak perlakuan diisi 4 liter air (sisa Budidaya Udang Vaname selama 118 hari) dan di tambahkan konsorsium bakteri $3 \mathrm{gram} / \mathrm{L}$ lalu ditambahkan mikroalga dengan kepadatan $10^{4} \mathrm{sel} / \mathrm{ml}, 10^{5} \mathrm{sel} / \mathrm{ml}$ dan $10^{6} \mathrm{sel} / \mathrm{ml}$. Pengamatan fisika kimia air dan mikroalga dilakukan setiap 6 jam selama 72 jam. Hasil penelitian menunjukkan semua perlakuan mengalami penurunan bahan organik yang nilainya hampir sama dengan kontrol. Kadar karbondioksida mengalami penurunan dari kadar $11,88 \mathrm{mg} / \mathrm{L}$ menjadi $0 \mathrm{mg} / \mathrm{L}$ setelah $72 \mathrm{jam}$. Kadar bahan organik mengalami penurunan dari-39.2 mg/l menjadi $0.2 \mathrm{mg} / \mathrm{l}$ setelah 54 jam. Selama penelitian suhu berkisar antara $23-26^{\circ} \mathrm{C}, \mathrm{pH} 7-9$, oksigen terlarut $6,0-9,3 \mathrm{mg} / \mathrm{l}$, salinitas $10-13 \mathrm{mg} / \mathrm{l}$. Dapat disimpulkan bahwa bahan organik dapat menurun sampai dengan $99,7 \%$ setelah 54 jam dan $\mathrm{CO}_{2}$ dapat menurun sampai $100 \%$ setelah 72 jam.Apabila diperlukan penambahan mikroalga untuk membantu menurunkan kadar $\mathrm{CO}_{2}$, maka disarankan menggunakan kepadatan mikroalga $10^{6} \mathrm{sel} / \mathrm{ml}$ atau $55.5 \mathrm{ml} / \mathrm{L}$ agar tidak terjadi blooming mikroalga di perairan umum.
\end{abstract}


Panduan Sitasi (APPA $7^{\text {th }}$ edition) :

Pratiwi, R. K., \& Arfiati, D. (2021). Upaya Penurunan Bahan Organik Air Sisa Budidaya Udang Vaname (Litopenaeus Vannamei) dengan Konsorsium Bakteri dan Kepadatan Chlorella sp. Yang Berbeda. Jurnal Pengabdian Perikanan Indonesia, 1 (3), 188-195. http://doi.org/ 10.29303/jppi.v1i3.341

\section{PENDAHULUAN}

Perkembangan sistem budidaya udang dari budidaya ekstensif menjadi budidaya intensif berdampak buruk bagi lingkungan, karena menyebabkan peningkatan bahan organic yang berpotensi mencemari perairan umum di sekitarnya. Berdasarkan penelitian dari Tangguda dan Prasetia (2019) menyatakan bahwa, pencemaran dapat diakibatkan oleh penumpukan bahan organik yang sebagian besar berasal dari sisa pakan yang tidak mampu dimanfaatkan secara optimal oleh organisme budidaya.

Upaya pengolahan limbah sebelum masuk ke perairan umum perlu dilakukan untuk meminimalkan dampak negatif dari limbah cair tambak, salah satunya dengan pengolahan secara biologi (Zalfiatri et al., 2017). Metode pengelolaan air secara biologi dapat dilakukan dengan menambahkan bakteri pengurai, Umumnya proses degradasi di lingkungan dilakukan oleh konsorsium mikroba bukan satu jenis mikroba saja (Thompson et al., 2005). Berdasarkan penelitian Oktavia \& Yanuar (2017), penurunan bahan organik yang dilakukan dengan konsorsium bakteri mampu menurunkan bahan organik dalam limbah cair perikanan hampir sebesar 70,27 \%. Menurut Badjoeri dan Widiyanto (2008), bioremediasi merupakan pendekatan biologis dalam pengelolaan kualitas air tambak dengan memanfaatkan aktivitas enzimatik bakteri dalam merombak bahan organik. Mikroba memanfaatkan senyawa organik yang terdapat dalam air limbah sebagai sumber nutrisi. Mikroba akan mengurai senyawa tersebut menjadi bentuk yang lebih sederhana dan stabil sehingga kadar zat pencemar yang terkandung dalam air limbah tersebut menjadi turun.

Proses penguraian bahan organik juga menghasilkan senyawa karbondioksida $\left(\mathrm{CO}_{2}\right)$ berlebih dan mikroalga mampu memanfaatkan $\mathrm{CO}_{2}$ tersebut sebagai sumber karbon utama untuk sintesis sel baru sehingga dapat mengurangi kelebihan senyawa karbondioksida pada proses degradasi bahan organik di perairan. Restuhadi, et al. (2017) menyatakan bahwa Chlorella sp. dapat digunakan sebagai penstabil limbah, karena alga mampu bersimbiosis dengan bakteri pengoksidasi. Abdurrachman et al., (2013), alga hijau Chlorella sp. memiliki kemampuan untuk menyerap karbondioksia $\left(\mathrm{CO}_{2}\right)$ untuk reproduksi sel-sel tubuhnya sehingga mengurangi kadar karbondioksida $\left(\mathrm{CO}_{2}\right)$ didalam air yang meningkat diperairan akibat dari hasil degradasi bahan organik oleh bakteri.

Berdasarkan uraian diatas, maka perlu dilakukan penelitian mengenai variasi kepadatan mikroalga Chlorella sp. yang dalam medianya ditambahkan konsorsium bakteri sebanyak $3 \mathrm{gram} / \mathrm{L}$ agar air sisa budidaya tersebut tidak menambah beban pencemar ke perairan umum. Berdasarkan hasil penelitian dari Khairul (2017), bahwa penurunan bahan organik terbaik yang dilakukan oleh konsorsium bakteri adalah sebanyak $12 \mathrm{ml}$ dalam 4 liter air.

\section{METODE KEGIATAN}

Kegiatan ini menggunakan metode eksperimen dengan Rancangan Acak Lengkap (RAL) Perlakuannya yaitu penambahan mikroalga dengan kepadatan mikroalga $10^{4} \mathrm{sel} / \mathrm{ml}, 10^{5} \mathrm{sel} / \mathrm{ml}$ dan $10^{6} \mathrm{sel} / \mathrm{ml}$. semua bak perlakuan ditambah dengan konsorsium bakteri sebanyak $3 \mathrm{~g} / \mathrm{L}$. dalam penelitian ini terdapat 2 jenis kontrol yang terdiri dari kontrol dengan pemberian bakteri tetapi tanpa 
penambahan mikroalga dan cahaya, serta kontrol tanpa penambahan mikroalga dan tanpa bakteri.

Toples dengan volume 10 liter ( 24 buah) di isi Air sampel dimasukkan ke dalam dengan masingmasing toples diisi sebanyak 4 liter kemudian dimasukkan dosis mikroalga pada masing-masing toples dengan kepadatan $10^{4} \mathrm{sel} / \mathrm{ml}, 10^{5} \mathrm{sel} / \mathrm{ml}$ dan $10^{6} \mathrm{sel} / \mathrm{ml}$. Pada toples yang telah berisi air sisa budidaya dan mikroalga kemudian ditambahkan bakteri BIO 2000 dengan dosis yang sama yaitu 4 gram/toples ke dalam semua toples kecuali toples kontrol. Penelitian dilakukan selama 3 hari atau 72 jam dengan pengukuran kadar bahan organik total dan parameter kualitas air (suhu, pH, oksigen terlarut, salinitas dan karbondioksida) setiap 6 jam. Sampel air yang digunakan merupakan sisa kegiatan budidaya selama kurang lebih 118 hari doc (day of culture). Pengambilan air sampel dilakukan pada bagian pembuangan (outlet). Sebanyak 96 liter sampel dikemas dalam beberapa botol plastik, selanjutnya dimasukan dalam cool box berisi es dan dibawa ke laboratorium dengan perjalanan kurang lebih 5 jam.

Bahan Organik Total (BOT) Kandungan bahan organik total pada air limbah di ukur menggunakan metode titrasi menggunakan oksidator $\mathrm{KMnO}_{4}$ dengan menggunakan rumus akhir sebagai berikut:

$$
\text { BOT }=\frac{(X-Y) 31,6 \times 0,01 \times 1000}{V \text { air sampel }}
$$

\section{Karbondioksida $\left(\mathrm{CO}_{2}\right)$}

Karbondioksida pada air limbah di ukur menggunakan metode titrasi $\mathrm{Na}_{2} \mathrm{CO}_{3}$ dengan indikator PP dengan menggunakan rumus akhir sebagai berikut:

$$
\text { CO2 }=\frac{V \text { titran } \times N \text { titran } \times 22 \times 1000}{\text { volume sampel }}
$$

\section{Suhu, Oksigen terlarut, pH, Salinitas}

Parameter kualitas air selain Bahan organik dan $\mathrm{CO}_{2}$ yang diukur pada penelitian ini yaitu suhu, $\mathrm{pH}$, oksigen terlarut dan salinitas. Suhu dan oksigen terlarut diukur menggunakan $\mathrm{DO}$ meter, $\mathrm{pH}$ diukur dengan $\mathrm{pH}$ paper dan salinitas diukur dengan refraktometer.

\section{Analisis Data}

Hasil pengukuran fisika kimia air yang diperoleh selanjutnya dianalisis dengan Anova Faktorial dengan Aplikasi SPSS IBM 25 untuk mengetahui pengaruh pemberian mikroalga dengan kepadatan berbeda terhadap penurunan bahan organik setiap 6 jam selama 72 jam pengamatan. Jika diperoleh hasil yang berpengaruh nyata, dilanjutkan dengan uji Tukey untuk mengetahui kepadatan terbaik mikroalga (Chlorella sp.) pada media yang ditambahkan konsorsium bakteri BIO 2000 dalam menurunkan $\mathrm{CO}_{2}$ dan bahan organik sampai tingkat terendah dengan waktu tercepat pada air sisa budidaya intensif Udang Vaname.

\section{HASIL DAN PEMBAHASAN}

\section{Bahan Organik}

Pada penelitian ini didapatkan hasil bahan organik awal sebesar $39 \mathrm{mg} / \mathrm{L}$. Berdasarkan analisis of varian (ANOVA) didapatkan nilai Sig. $=0,000<\alpha=0,05$ yang berarti $\mathrm{HO}$ ditolak dan $\mathrm{H} 1$ diterima atau Kepadatan Chlorella sp. dan konsorsium bakteri BIO 2000 dapat menurunkan bahan organik pada air 
sisa budidaya Udang Vaname di Tambak Budidaya Udang PT Anugerah Tanjung Gumukmas (ATG), Kabupaten Jember. Grafik hasil pengukuran bahan organik secara keseluruhan dapat dilihat pada Gambar 1. Berdasarkan grafik di bawah didapatkan hasil bahwa setiap jamnya bahan organik mengalami penurunan dari jam ke 6 sampai dengan jam ke 72. Penurunan yang optimal terjadi pada jam ke 54. Kadar tertinggi bahan organik pada penelitian tersebut yaitu sebesar $39,2 \mathrm{mg} / \mathrm{L}$ dan nilai terendah yaitu $0.2 \mathrm{mg} / \mathrm{L}$. Berdasarkan uji lanjutan Tukey didapatkan hasil penurunan bahan organik terbaik pada perlakuan AP3 (Penambahan bakteri dan Chlorella dengan kepadatan $10^{4} \mathrm{sel} / \mathrm{ml}$ ) dengan efisiensi penurunan sebesar 99,4\% (dari kadar $39,2 \mathrm{mg} / \mathrm{L}$ menjadi kadar $0.2 \mathrm{mg} / \mathrm{L}$ ).

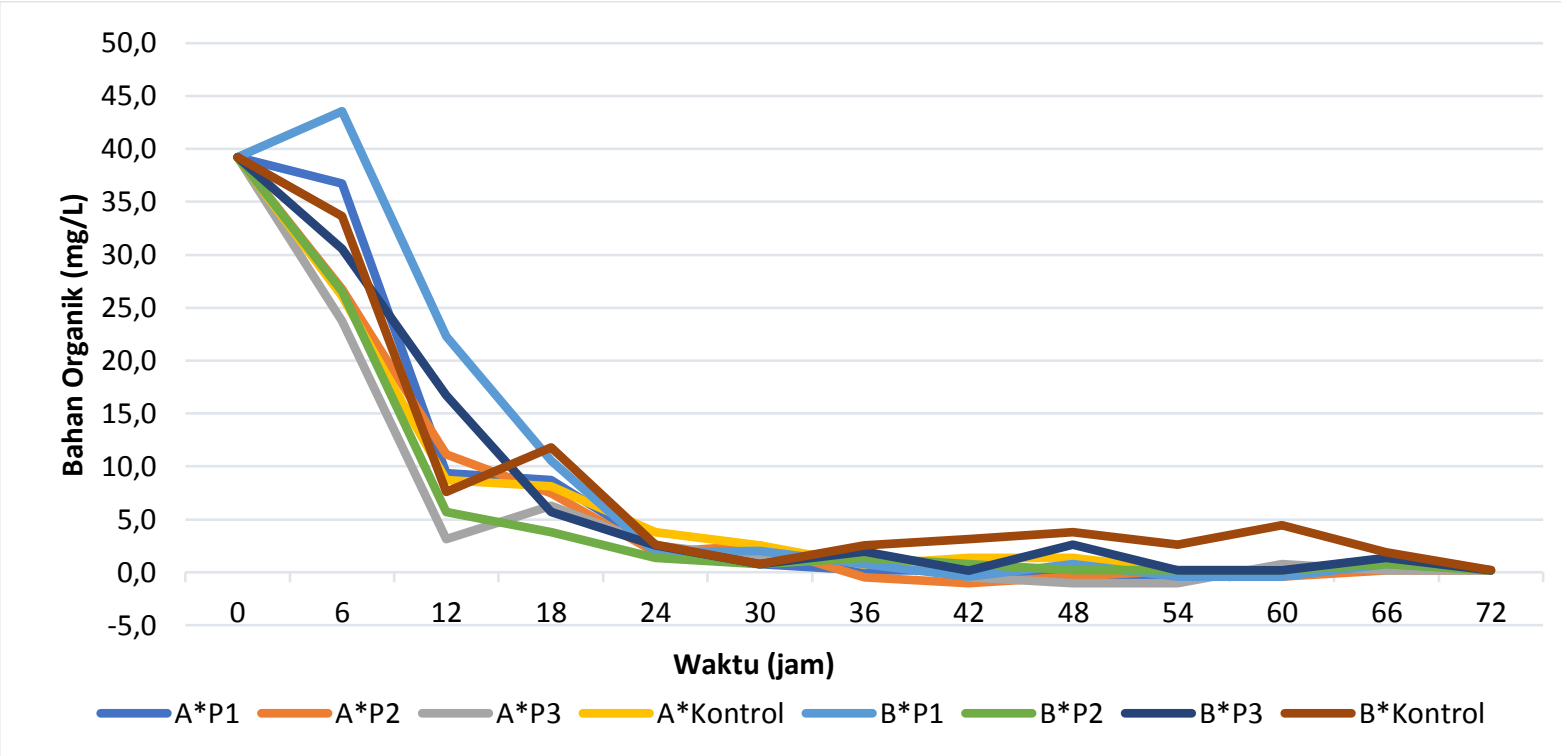

Gambar 1. Grafik Hasil Pengukuran Bahan Organik

Bahan organik merupakan sumber nutrien bagi biota perairan yang berada di dasar substrat. Tetapi apabila kadarnya melebihi baku mutu, maka dapat membawa dampak negatif terhadap lingkungan perairan. Selain itu, dapat memicu adanya bahan pencemar lain dengan meningkatkan kadar karbondioksida. Bahan organik dapat dimanfaakan oleh mikroorganisme seperti bakteri untuk proses pertumbuhannya.

Berdasarkan Gambar 1 dapat diketahui bahwa setiap jam bahan organik mengalami penurunan dari jam ke 6 sampai dengan jam ke 72. Penurunan tersebut disebabkan adanya bakteri konsorsium BIO 2000. Kadar bahan organik tersebut bersifat fluktuatif, yaitu mengalami naik turun yang terjadi pada beberapa jam tertentu. Namun, penurunan yang optimal terjadi pada jam ke 54 . Berdasarkan uji lanjutan Tukey didapatkan hasil penurunan bahan organik terbaik pada perlakuan AP3 (Penambahan bakteri dan Chlorella dengan kepadatan $10^{6} \mathrm{sel} / \mathrm{ml}$ ) dengan penurunan sebesar 99,4\% (dari kadar 39,2 mg/L menjadi kadar $0.2 \mathrm{mg} / \mathrm{L}$ ). Penurunan terendah diperoleh pada perlakuan BP1 (penambahan mikroalga dengan kepadatan $10^{6} \mathrm{sel} / \mathrm{ml}$ pada media tanpa ditambahkan (bakteri) dengan penurunan sebesar 97,9\%. Kadar bahan organik yang aman bagi lingkungan perairan menurut Supriyantini et al., (2017), yaitu $\leq 30 \mathrm{mg} / \mathrm{l}$ dengan demikian sisa kadar bahan organik pada perlakuan AP3 dengan kadar bahan organik $0.2 \mathrm{mg} / \mathrm{l}$ sudah aman untuk dibuang ke perairan umum.

Bahan organik mampu mengalami penurunan dengan cepat karena adanya mikroorganisme yang memanfaatkan bahan organik untuk pertumbuhannya. Menurut Ryanto, et al. (2012), adanya penurunan bahan organik diduga disebabkan oleh aktivitas mikroorganisme yang mengurai bahan organik dalam sedimen tersebut menjadi komponen-komponen lainnya. 


\section{Karbondioksida}

Pada penelitian ini didapatkan hasil kadar karbondioksida awal sebesar $11.88 \mathrm{mg} / \mathrm{L}$. Berdasarkan analisis of varian (ANOVA) didapatkan nilai Sig. $=0,000<\alpha=0,05$ yang berarti $\mathrm{HO}$ ditolak dan H1 diterima atau Kepadatan Chlorella sp. dan konsorsium bakteri BIO 2000 dapat menurunkan karbondioksida pada air sisa budidaya Udang Vaname di Tambak Budidaya Udang PT Anugerah Tanjung Gumukmas (ATG), Kabupaten Jember. Grafik hasil pengukuran

dapat dilihat pada Gambar 2. Berdasarkan grafik di bawah didapatkan hasil bahwa setiap jamnya karbiondioksida mengalami penurunan dari jam ke 6 sampai dengan jam ke 72 . Penurunan karbondioksida yang optimal terjadi pada jam ke 72. Kadar karbondioksida pada penelitian tersebut yaitu sebesar $11,88 \mathrm{mg} / \mathrm{L}$ dan nilai terendah yaitu $0 \mathrm{mg} / \mathrm{L}$. Berdasarkan uji lanjutan Tukey didapatkan hasil penurunan karbondioksida terbaik pada perlakuan AP1 dengan efisiensi penurunan sebesar $100 \%$ (dari kadar $11.88 \mathrm{mg} / \mathrm{L}$ menjadi kadar $0 \mathrm{mg} / \mathrm{L}$ ).

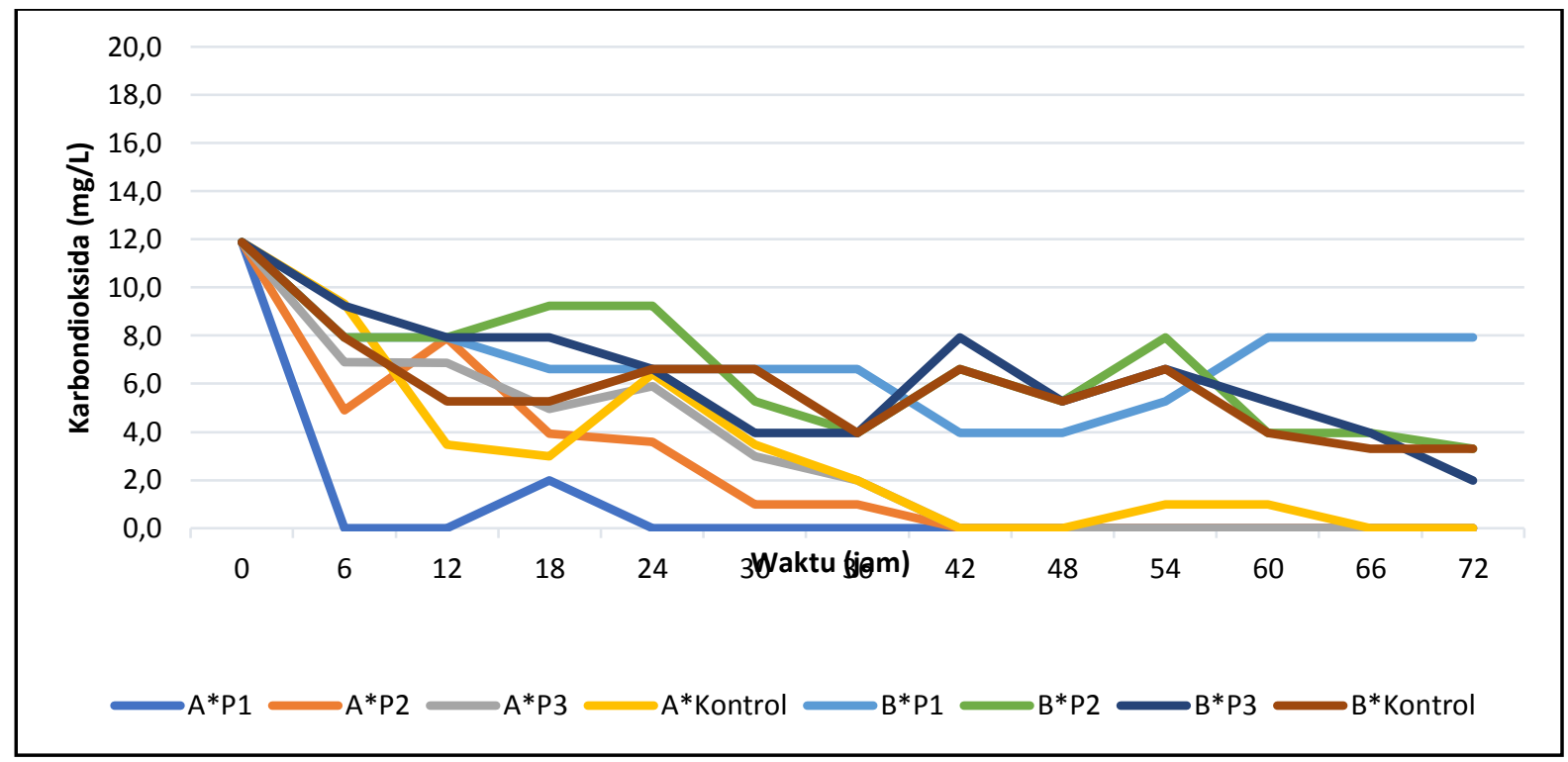

Gambar 2. Grafik Hasil Pengukuran Karbondioksida

Pada penelitian ini didapatkan hasil kadar karbondioksida awal sebesar $11.88 \mathrm{mg} / \mathrm{L}$. Berdasarkan analisis of varian (ANOVA) didapatkan nilai Sig. $=0,000<\alpha=0,05$ yang berarti $\mathrm{H}_{0}$ ditolak dan $\mathrm{H}_{1}$ diterima atau Kepadatan Chlorella sp. dan konsorsium bakteri BIO 2000 dapat menurunkan karbondioksida pada air sisa budidaya udang. Grafik hasil pengukuran bahan organik secara keseluruhan dapat dilihat pada Gambar 2 bahwa setiap 6 jam pengukuran kadar karbiondioksida menurun dari jam ke 6 sampai dengan jam ke 72. Penurunan tersebut karena adanya pemanfaatan $\mathrm{CO}_{2}$ oleh Chlorella sp. yang dimanfaatkan dalam proses fotosintesis.

Penurunan karbondioksida pada jam ke 72 diperoleh kadar terendah dari 11,88 mg/L menjadi $0 \mathrm{mg} / \mathrm{L}$. Berdasarkan uji lanjutan Tukey didapatkan hasil penurunan bahan organik terbaik AP1 (penambahan mikroalga dengan kepadatan $10^{6} \mathrm{sel} / \mathrm{ml}$ ). Penurunan terendah merupakan perlakuan BP1 (Penambahan mikroalga dengan kepadatan $10^{6} \mathrm{sel} / \mathrm{ml}$ tanpa adanya penambahan bakteri). Asis et al., (2017) menjelaskan bahwa pada konsentrasi tinggi ( $>10 \mathrm{mg} / \mathrm{l}$ ), karbondioksida dapat beracun karena adanya $\mathrm{CO}_{2}$ di dalam darah dapat menekan aktivitas pernapasan ikan dan menghambat pengikatan oksigen oleh hemoglobin sehingga dapat membuat ikan menjadi stress, dengan demikian kadar karbondioksida pada perlakuan AP1 dengan sisa kadar sebesar $0 \mathrm{mg} / \mathrm{L}$ aman untuk masuk ke perairan umum. 


\section{Kualitas Air}

Tabel 1. Hasil Pengukuran Kualitas Air

\begin{tabular}{lc}
\hline \multicolumn{1}{c}{ Kualitas Air } & Hasil \\
\hline Suhu & $23-26^{\circ} \mathrm{C}$ \\
Oksigen Terlarut & $6.0-9.3 \mathrm{mg} / \mathrm{L}$ \\
$\mathrm{pH}$ & $7-9$ \\
Salinitas & $10-13 \mathrm{ppt}$ \\
Karbondioksida & $0 \mathrm{mg} / \mathrm{L}$ \\
Bahan Organik & $0.2 \mathrm{mg} / \mathrm{L}$ \\
\hline
\end{tabular}

Hasil pengukuran parameter kualitas air seperti suhu, pH, oksigen terlarut dan salinitas dalam kondisi optimum untuk perairan. Peran bakteri dalam menguraikan bahan organik akan berjalan optimal apabila faktor pendukung seperti suhu, $\mathrm{pH}$ oksigen terlarut dan salinitas dalam kondisi optimal (Purnomo et al., 2013).

\section{Suhu}

Pada penelitian ini dilakukan pengukuran suhu dengan menggunakan DO meter. Hasil pengukuran suhu yaitu berkisar antara $23^{\circ} \mathrm{C}-26^{\circ} \mathrm{C}$. Pada penelitian ini didapatkan hasil suhu dengan nilai terendah yaitu sebesat $23^{\circ} \mathrm{C}$ dan tertinggi sebesar $26^{\circ} \mathrm{C}$. Suhu yang lebih hangat cenderung dapat mempercepat proses dekomposisi oleh bakteri. Berdasarkan penelitian Situngkir et al., (2019), kondisi perairan dengan suhu berkisar $29^{\circ} \mathrm{C}$ dapat membantu mikroorganisme dalam kegiatan penguraian bahan organik menjadi unsur yang tidak berbahaya pada suatu perairan tambak.

\section{pH}

Pengukuran $\mathrm{pH}$ dilakuakn dengan menggunakan $\mathrm{pH}$ paper. Hasil pengukuran $\mathrm{pH}$ yaitu berkisar antara 7-9. Pada penelitian ini didapatkan hasil nilai $\mathrm{pH}$ terendah yaitu 7 dan nilai $\mathrm{pH}$ tertinggi berada di angka 9. Pada penelitian ini, parameter $\mathrm{pH}$ memiliki fluktuasi yang signifikan pada setiap pengukurannya. $\mathrm{pH}$ merupakan salah satu parameter yang penting dalam kehidupan organisme yang digunakan untuk menyatakan kadar asam atau basa suatu larutan(Lasindrang, 2014). pH pada perairan erat kaitannya dengan kadar karbondioksida pada perairan. Semakin tinggi kadar karbondioksida maka nilai $\mathrm{pH}$ akan semakin rendah atau asam. Yuspita et al., (2018), menyatakan bahwa nilai pH yang baik untuk perombahan bahan organik oleh bakteri adalah berkisar 7,68-8,05.

\section{Oksigen Terlarut}

Pada penelitian ini didapatkan nilai oksigen terlarut terendah yaitu $6,0 \mathrm{mg} / \mathrm{L}$ dan nilai oksigen terlarut tertinggi yaitu 9,3 $\mathrm{mg} / \mathrm{L}$. oksigen terlarut tersebut mengalami fluktuasi yang signifikan disetiap harinya. Adanya peningkatan oksigen terlarut disebabkan oleh perlakuan mikroalga Chlorella sp. yang ada di dalam toples.. Kisaran oksigen terlarut yang baik untuk bakteri yaitu $0,42-7,90 \mathrm{mg} / \mathrm{l}$. Sidharta (2000) menyebutkan mikroorganisme seperti bakteri dapat hidup pada lingkungan dengan ketersediaan oksigen (bakteri aerob) hingga lingkungan tanpa oksigen (bakteri anaerob).

\section{Salinitas}

Nilai salinitas terendah sebesar 10 ppt dan nilai salinitas tertinggi sebesar 13 ppt. Nilai salinitas pada penelitian ini tergolong rendah karena air sampelnya merupakan air payau. Menurut Annisa (2021), salinitas adalah tingkat keasinan atau kadar garam terlarut dalam air. Salinitas merupakan salah 
satu faktor yang sangat menentukan perkembangan fitoplankton, terutama dalam mempertahankan tekanan osmosis antara protoplasma sel dengan air sebagai lingkungannya. Salinitas yang terlalu tinggi atau terlalu rendah dapat mengakibatkan aktifitas sel terganggu. Menurut Rudiyanti (2011), sebagian besar plankton sangat peka terhadap perubahan kadar garam dalam air. Pernyataan Djunaedi et al., (2017), Chlorella vulgaris dapat tumbuh optimal pada salinitas 10-35 ppt.

\section{KESIMPULAN}

Pada penelitian ini didapatkan kadar bahan organik terendah yaitu $0.2 \mathrm{mg} / \mathrm{L}$ dengan perlakuan penurunan bahan organik dalam waktu tercepat di waktu 54 jam pada penambahan mikroalga dengan kepadatan $10^{4} \mathrm{sel} / \mathrm{ml}$. Untuk menurunkan kadar karbondioksida sampai dengan kadar $0 \mathrm{mg} / \mathrm{L}$ dapat digunakan kepadatan mikroalga Chlorella sp. dengan kepadatan $10^{6} \mathrm{sel} / \mathrm{ml}$, pada jam ke 72 . Karbondioksida awal $11.88 \mathrm{mg} / \mathrm{l}$ menjadi $0 \mathrm{mg} / \mathrm{l}$ atau menurun sebesar $100 \%$ dalam waktu 3 hari.

\section{UCAPAN TERIMA KASIH}

Ucapan terimakasih kepada teman - teman dan semua pihal yang terlibat mensukseskan penelitian ini. Yang selalu memberikan perhatian dengan penuh kesabaran, serta memberikan saran masukan dan motivasi baik secara langsung maupun tidak kepada penulis dalam menyelesaikan artikel ini.

\section{DAFTAR PUSTAKA}

Abdurrachman, O., Mutiara, M., \& Buchori, L. (2013). Pengikatan karbon dioksida dengan mikroalga (Chlorella vulgaris, Chlamydomonas sp., Spirullina sp.) Dalam upaya untuk meningkatkan kemurnian biogas. Jurnal Teknologi Kimia Dan Industri, 2(4), 212-216. https://ejournal3.undip.ac.id/index.php/jtki/article/view/4056/3948

Annisa, A. I. (2021). Analisis karakteristik sedimen dan bahan organik di Banyuurip Mangrove Center (BMC) Gresik: di Banyuurip Mangrove Center (BMC) Gresik (Doctoral dissertation, UIN Sunan Ampel Surabaya). (Disertasi) UIN Sunan Ampel Surabaya. http://digilib.uinsby.ac.id/id/eprint/46792

Asis, A., Sugihartono, M., \& Ghofur, M. (2017). Pertumbuhan ikan patin siam (Pangasianodon hypopthalmus F.) pada pemeliharaan sistem akuaponik dengan kepadatan yang berbeda. Jurnal $\begin{array}{llll}\text { Akuakultur Sungai Dan 2(2), 51-57. } & \text { Danau, }\end{array}$ https://doi.org/http://dx.doi.org/10.33087/akuakultur.v2i2.17

Djunaedi, A., Sunaryo, S., Suryono, C. A., \& Santosa, A. (2017). Kandungan Pigmen Fikobiliprotein dan Biomassa Mikroalga Chlorella vulgaris pada media dengan Salinitas Berbeda. Jurnal Kelautan Tropis, 20(2), 112-116. https://doi.org/https://doi.org/10.14710/jkt.v20i2.1736

Khairul, K. (2017). Pemberian dosis probiotik berbeda terhadap kelulusan benur udang windu (Penaeus monodon fabricius). Jurnal Pembelajaran Dan Biologi Nukleus, 3(1), 25-29. https://doi.org/https://doi.org/10.36987/jpbn.v3i1.1199

Lasindrang, M. (2014). Adsorpsi pencemaran limbah cair industri penyamakan kulit oleh kitosan yang melapisi arang aktif tempurung kelapa. Jurnal Teknosains, 3(2). https://doi.org/https://doi.org/10.22146/teknosains.6026

Oktavia, D., \& Yanuar, V. (2017). Pengolahan air limbah tepung ikan menggunakan bioremedian komersil dan konsorsium bakteri. Prosiding Seminar Nasional Tahunan XIV Hasil Penelitian Perikanan Dan Kelautan.

Purnomo, P. W., Nitisupardjo, M., \& Purwandari, Y. (2013). Hubungan Antara Total Bakteri Dengan Bahan Organik, No3 Dan H2S Pada Lokasi Sekitar Eceng Gondok Dan Perairan Terbuka Di Rawa Pening. Management of Aquatic Resources Journal (MAQUARES), 2(3), 85-92. https://doi.org/10.14710/marj.v2i3.4186 
Rudiyanti, S. (2011). The Growth of Skeletonema costatum on Various Salinity Level's Media. Indonesian Journal of Fisheries Science and Technology, 6(2), 70-77. https://doi.org/https://doi.org/10.14710/ijfst.6.2.70-77

Situngkir, Y. A., Sari, A. H. W., \& Perwira, I. Y. (2019). Tingkat Dekomposisi Bahan Organik Pada Substrat Dasar Tambak Udang Vannamei (Litopenaeus vannamei) di Desa Patas Bagian Timur, Buleleng, Bali. Current Trends in Aquatic Science, 2(2), 79-86. https://ojs.unud.ac.id/index.php/CTAS/article/download/50449/33368.

Supriyantini, E., Nuraini, R. A. T., \& Fadmawati, A. P. (2017). Studi kandungan bahan organik pada beberapa muara sungai di kawasan ekosistem mangrove, di wilayah pesisir pantai Utara Kota Semarang, Jawa Tengah. Buletin Oseanografi Marina, 6(1), 29-38. https://doi.org/https://doi.org/10.14710/buloma.v6i1.15739.

Thompson, I. P., Gast, C. J. V. D., Ciric, L., \& Singer, A. C. (2005). Bioaugmentation for bioremediation: the challenge of strain selection. Environmental Microbiology, 7(7), 909-915. https://doi.org/https://doi.org/10.1111/j.1462-2920.2005.00804.x

Yuspita, N. L. E., Putra, I. D. N. N., \& Suteja, Y. (2018). Bahan Organik Total dan Kelimpahan Bakteri di Perairan Teluk Benoa, Bali. Jurnal of Marine and Aquatic Sciences, 4(1), 129-140. https://ojs.unud.ac.id/index.php/jmas/article/download/34225/20598

Zalfiatri, Y., Restuhadi, F., \& Maulana, T. (2017). Pemanfaatan simbiosis mikroorganisme b-deco3 dan mikroalga chlorella sp untuk menurunkan pencemaran limbah cair pabrik kelapa sawit. Dinamika Lingkungan Indonesia, 4(1), 8-17. https://doi.org/http://dx.doi.org/10.31258/dli.4.1.p.8-17 